\title{
Flow characteristics in flow networks
}

\author{
N. Zhang, W.-J. Yang and Y. Xu \\ Department of Mechanical Engineering and Applied Mechanics, The University of Michigan, Ann Arbor, MI 48109, USA
}

\section{P. Lee}

General Electric Company, Cincinnati, Ohio 45215, USA

\begin{abstract}
A flow network is a system of mutually intersecting holes in a plate or an assembly of plates. The flow at each intersection is characterized by a collision of two flow streams, resulting in complex flow patterns through the downstream holes. In the case of multiple intersections, the flow is periodically disrupted at each succeeding intersection, thus preventing the formation of a fully-developed flow through the holes.

An experimental study is presented in this paper to determine flow characteristics in flow networks with various geometry. The intersecting pressure loss coefficient which represents the performance of flow networks is defined and its magnitude empirically determined as functions of geometric and flow conditions. A method is developed to measure the ramming loss in an intersection tube. Flow visualization by means of hydrogen bubble method is applied to observe flow patterns and mixing behavior in the flow network. A physical model is developed to predict the intersection pressure loss in flow networks.
\end{abstract}

\section{List of symbols}

\begin{tabular}{|c|c|}
\hline$A$ & tion area of the flow network holes \\
\hline & hole in the flow network \\
\hline$l_{t}$ & throat area of the orifice \\
\hline & semi-minor axis of the intersection throat ellipse (Fig. 8) \\
\hline$C_{d}$ & w discharge coefficient with intersection \\
\hline$C_{d 0}$ & $\begin{array}{l}\text { erall flow discharge coefficient in the absence of inter- } \\
\text { ction }\end{array}$ \\
\hline$D_{h}$ & Hraulic diameter of the flow channel \\
\hline & h \\
\hline$f$ & coefficient \\
\hline$F F$ & com \\
\hline$H$ & ection ellipse (Fig. 8) \\
\hline$K_{b}, K_{0}$ & $\begin{array}{l}\text { ssure loss coefficients for the miter bend, and quad- } \\
\text { it-edged orifice, respectively }\end{array}$ \\
\hline$K_{c}, K_{e}, K_{x}$ & $\begin{array}{l}\text { flow contraction, expansion, and intersection coeffi- } \\
\text { cients, respectively }\end{array}$ \\
\hline$L$ & $\begin{array}{l}\text { length of the hole in the flow network, i.e. flow length } \\
\text { inside holes }\end{array}$ \\
\hline$L_{e}$ & $\begin{array}{l}\text { equivalent length of a pipe for the miter bend pressure } \\
\text { loss }\end{array}$ \\
\hline$N_{h}$ & flow network \\
\hline$N_{x}$ & s for each hole \\
\hline & h distance between holes \\
\hline$p_{a}, p_{s}, p_{t}$ & $\begin{array}{l}\text { gauge total pressure in the plenum, the ambient pres- } \\
\text { sure, and absolute total pressure in the plenum, respec- } \\
\text { tively }\end{array}$ \\
\hline$\Delta p_{b}$ & $\begin{array}{l}\text { pressure losses in the miter bend and through the quad- } \\
\text { rant-edged orifice, respectively }\end{array}$ \\
\hline
\end{tabular}

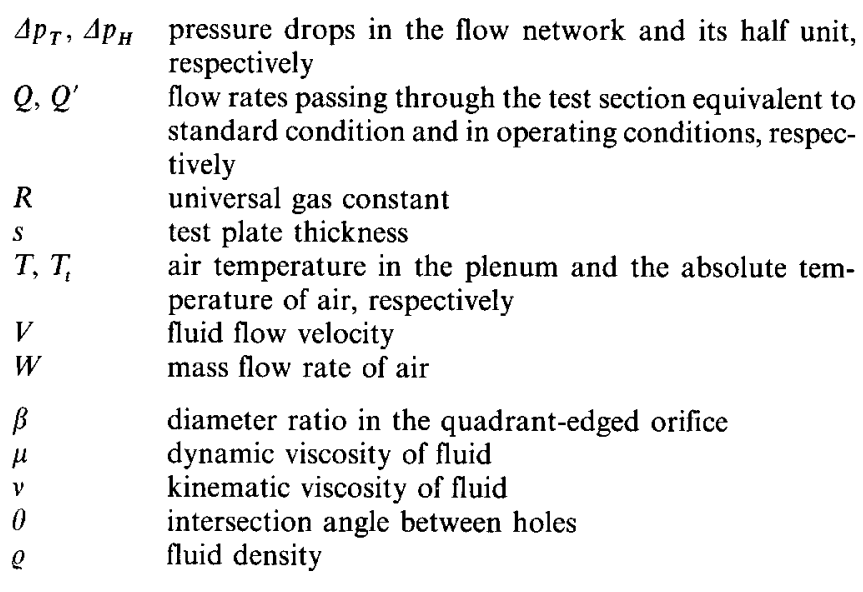

\section{Introduction}

The pressure losses due to sudden enlargement and/or sudden contraction of a cross section of pipe are of importance to flow in a pipeline. They may be calculated with both the energy and the momentum equations. Two dimensionless coefficients are employed to represent the magnitude of the losses: $K_{c}$ and $K_{e}$ for sudden contraction and enlargement, respectively.

A flow network is a system of mutually intersecting holes inside a plate or an assembly of plates. Figure 1 depicts the cross-sectional view of a flow network with a single intersection (Fig. 1 a), for each stream of throughflow, and multiple intersections (Fig. 1 b). A flow network of multiple intersections may be instituted inside a single plate or in an assembly of plates each of which has a single intersection (Fig. 1 b). The flow at each intersection is characterized by a collision of two flow streams, resulting in complex flow patterns through the downstream holes. In the case of multiple intersections, the flow is periodically disrupted at each succeeding intersection, thus preventing the formation of a fully developed flow through the holes. Hence, it is expected that a flow network provides a better flow mixing, and consequently, a higher heat transfer performance. 

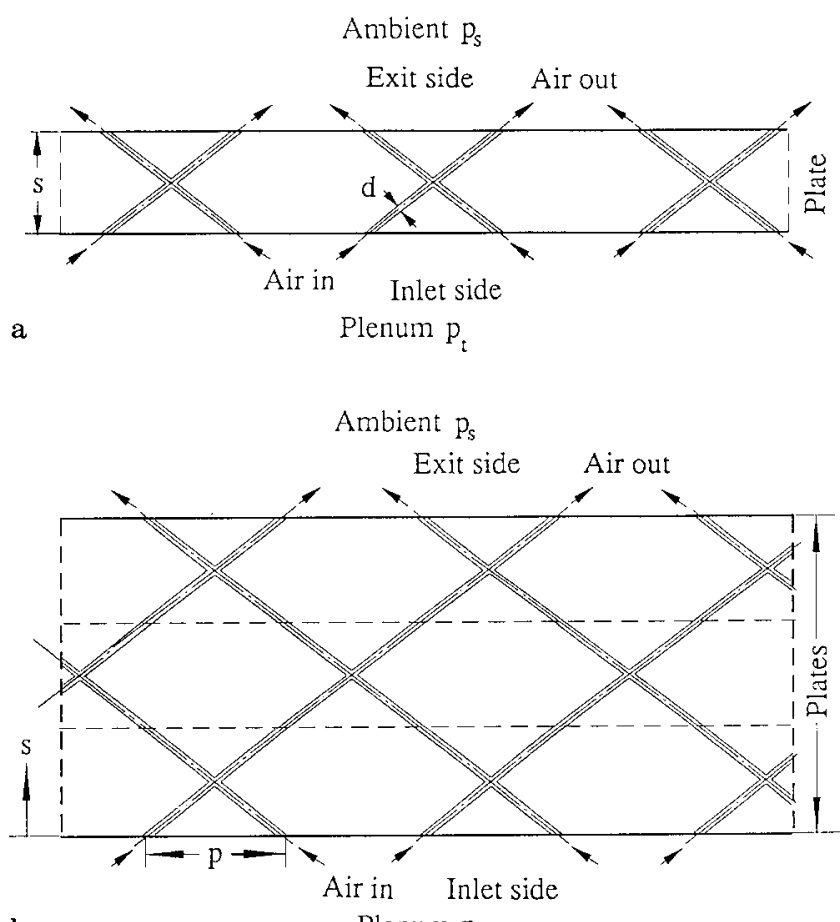

b

Plenum $p_{t}$

Fig. 1 a and b. Cross-sectional view of a flow network with a a single intersection and $\mathbf{b}$ multiple intersections

The flow characteristics, such as pressure drop and flow discharge coefficient, are important in sizing the network and predicting the flow rate through the network. They depend on the configuration of the flow network and the flow conditions. An accurate database is not available in the literature.

The purpose of this study is to obtain empirical flow and pressure drop data in various flow networks by systematically varying geometrical parameters and flow conditions. Results from the tests are correlated for design applications.

\section{Experimental apparatus and procedure}

\subsection{Pressure loss coefficients in flow networks}

The experimental apparatus used in the study is schematically shown in Fig. 2. It consisted of an air filter, two rotameters covering the flow rate (ranging from $4.72 \times 10^{-5}$ to $4.72 \times 10^{-4} \mathrm{~m}^{3} / \mathrm{s}$ ), a plenum for stabilizing air flow, a glass thermometer, three pressure gauges covering a broad pressure range with good accuracy, and a replaceable test section. The test section was designed to be versatile so that flow networks of different configurations could be tested without modification.

The flow networks were fabricated through flat plates, as schematically depicted in Fig. 1. A flow supply plenum was attached to the inlet side of the plate, while the flow exit side was exposed to ambient.

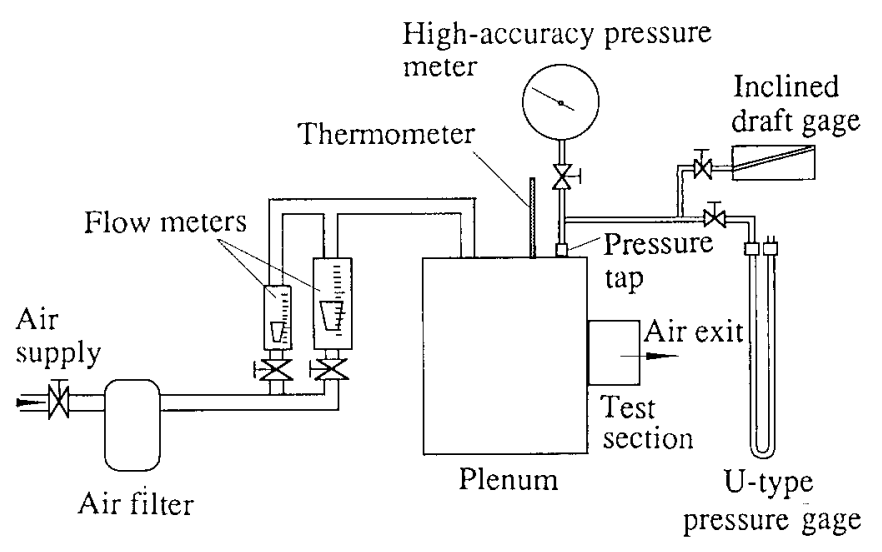

Fig. 2. Experimental setup

Air flow route is indicated by arrows. After the air filter, the flow was measured by one of the two flow meters, one for lower and the other for higher flow rates. The flow then entered the network via the plenum. The air temperature and pressure in the plenum were monitored. The high-accuracy pressure meter, the inclined draft gauge, or the U-type gauge was employed in pressure measurements, depending upon the magnitude.

Twenty different flow networks were fabricated and tested. Their geometric specifications are listed in Table 1. Here, $\theta$ denotes the intersection angle; $d$, hole diameter; $p$, pitch distance between holes; $N_{x}$, number of intersections for each hole; $s$, plate thickness; $L$, flow length inside holes; $p_{t} / p_{s}$, the pressure ratio of the upstream total to the downstream static pressure; and $N_{h}$, number of holes. Each configuration was tested at ten pressure ratios ranging from 1.0 to 2.0. These configuration cover various diameters, hole spacings flow lengths, number of intersections, and intersection angles.

During the test, the plenum pressure was varied to change the pressure ratio. The air temperature $T$, pressure $p_{a}$ and flow rate through the test section $Q$ were recorded. A conservative estimate showed that even if air flow was choked in the hole, the dynamic pressure in the plenum with section area of $0.186 \mathrm{~m}^{2}$ would be only $5.86 \times 10^{-3} \mathrm{~Pa}$. Hence, the pressure in the plenum may be treated as the upstream total pressure. Using the following procedure, the pressure data were reduced to yield the pressure loss coefficients, including the contraction coefficient $K_{c}$, expansion coefficient $K_{e}$, friction coefficient $f$, intersection coefficient $K_{x}$, and overall discharge coefficient $C_{d}$. In the calculations below, we use the following notation: $Q^{\prime}$, flow rate passing through the test section; $R$, gas constant; $T_{t}$, absolute air temperature; $\gamma$, specific heat ratio; $F F$, compressible flow function; $\varrho$, density of air; $v$, kinematic viscosity of air; $W$, mass flow rate of air; $C_{d 0}$, flow discharge coefficient in the absence of intersection; and $R e$, Reynolds number.

Measured parameters:

$p_{a}[\mathrm{~Pa}], T\left[{ }^{\circ} \mathrm{C}\right], Q[\mathrm{SCM} / \mathrm{s}], d[\mathrm{~m}]$ 
Table 1. Flow network study cases

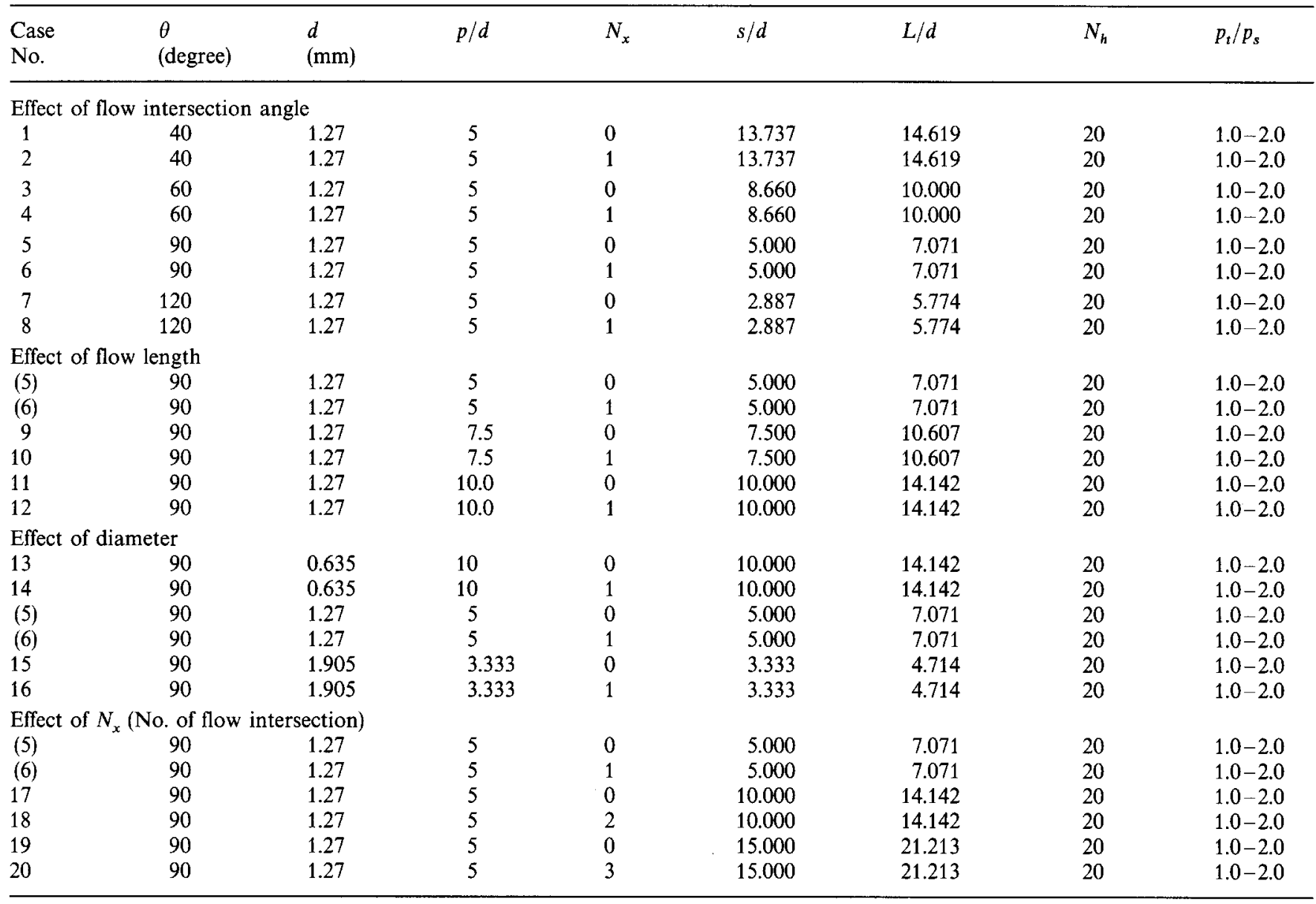

Constants:

$$
\begin{aligned}
& R=0.287 \mathrm{kN} \mathrm{m} /(\mathrm{kg} \mathrm{K}) \\
& p_{s}=101,325 \mathrm{~Pa} \\
& \gamma=1.4
\end{aligned}
$$

Calculations:

$p_{t}=p_{a}+101,325 \mathrm{~Pa}, \quad a=\frac{\pi d^{2}}{4} \mathrm{~m}^{2}, \quad A=20 a \mathrm{~m}^{2}$

$Q^{\prime}=Q \sqrt{\left(\frac{p_{a}+101,325}{101,325}\right)\left(\frac{21+273.16}{T+273.16}\right)} \mathrm{m}^{3} / \mathrm{s}$

$F F=\sqrt{\frac{2 \gamma}{R(\gamma-1)}}\left(\frac{p_{s}}{p_{t}}\right)^{\frac{1}{\gamma}} \sqrt{1-\left(\frac{p_{s}}{p_{t}}\right)^{\frac{\gamma-1}{\gamma}}}$

$\varrho=1.164-0.0036(T-20) \mathrm{kg} / \mathrm{m}^{3}$

$v=15.7+0.095(T-20) \mathrm{m}^{2} / \mathrm{s}$

$W=\varrho Q^{\prime} \mathrm{kg} / \mathrm{s}$

$T_{t}=T+273.16 \mathrm{~K}$

$\operatorname{Re}=\frac{Q^{\prime}}{A} \frac{d}{v}$

$\frac{1}{C_{d}}=\frac{p_{t} A}{W \sqrt{T_{t}}}(F F)$

$$
K_{x}=\frac{1}{C_{d}^{2}}-\frac{1}{C_{d 0}^{2}}
$$

\subsection{Pressure distribution in flow networks}

The pressure distribution in a flow network was determined following the same setup as Sect. 2.1 with the test section replaced by blow-up model. The model consisted of two $6.4 \mathrm{~mm} \times 6.4 \mathrm{~mm}$ square channels with an intersection angle of $60^{\circ}$. Figure 3 illustrates the location of 17 pressures taps of $1.6 \mathrm{~mm}$ diameter installed at strategic points. Taking advantage of symmetry, the lower half was made into a separate unit by blocking the symmetrical surface (illustrated by a broken line) with a solid plate. The pressure distribution in the lower half was measured to determine the difference in pressure distributions in a flow network with and without ramming.

\subsection{Flow visualization in flow networks}

A water model was employed to observe flow patterns in a flow network. The test setup consisted of a water filter, a 


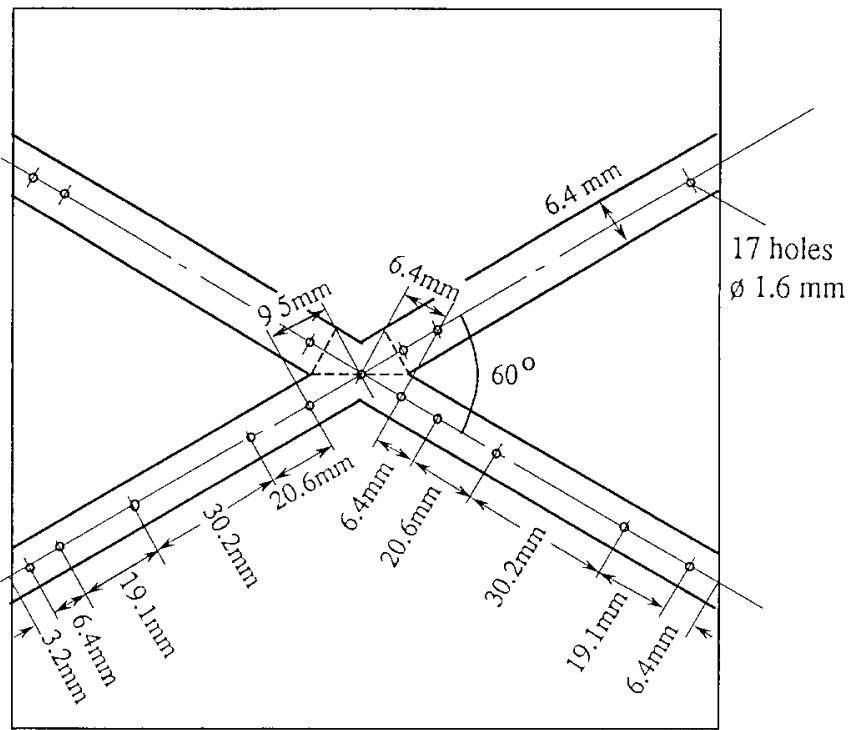

Fig. 3. Location of pressure measurements in a flow network with $\theta=60^{\circ}$ and its half unit

rotameter, a test section, two stabilizing plenums, an illumination system, a hydrogen-bubble generator and a camera, as shown in Fig. 4.

The pre-plenum was provided in order to maintain constant upstream pressure, while the after-plenum was open to ambient with an overflow rim. The test section was made of acrylic for visibility. It consisted of two $15.9 \mathrm{~mm} \times 15.9 \mathrm{~mm}$ square channels intersecting at an angle of $60^{\circ}$ and with the length-to-diameter ratio $L / d$ of 19.2. The hydrogen bubble generation system consisted of a pair of copper plates as the anodes, a pair of fine platinum wires as the cathodes, and a hydrogen bubble generator. Each cathode was placed at a distance of $127 \mathrm{~mm}$ from each entrance of the flow network.

\section{Results and discussion}

\subsection{Pressure loss coefficients}

The twenty cases listed in Table 1 were tested. Figure $5 \mathrm{a}-\mathrm{e}$ depicts the intersecting pressure loss coefficient $K_{x}$ and its dependence on the flow intersection angle, hole diameter, flow length, flow intersection number along each hole and Reynolds number, respectively. It is seen that $K_{x}$ diminishes with an increase in $R e$ within the tested range of $R e=500$ $\sim 15,000$ for all geometrical conditions with one exception: $\theta=60^{\circ}$. Two special features were observed in the flow network where $\theta=60^{\circ}$. For $R e$ in the range of 500 to 15,000 , $K_{x}$ remains constant, as seen in Fig. 5 a and takes a minimum value, as illustrated in Fig. $5 \mathrm{e}$. It should be noted that for $\theta=120^{\circ}, K_{x}$ changes significantly from 6.8 at $R e=500$ to 1.9 at $R e=15,000$, as depicted in Fig. 5 a. Figure 5 b shows that the larger the hole diameter, the higher the value of $K_{x}$

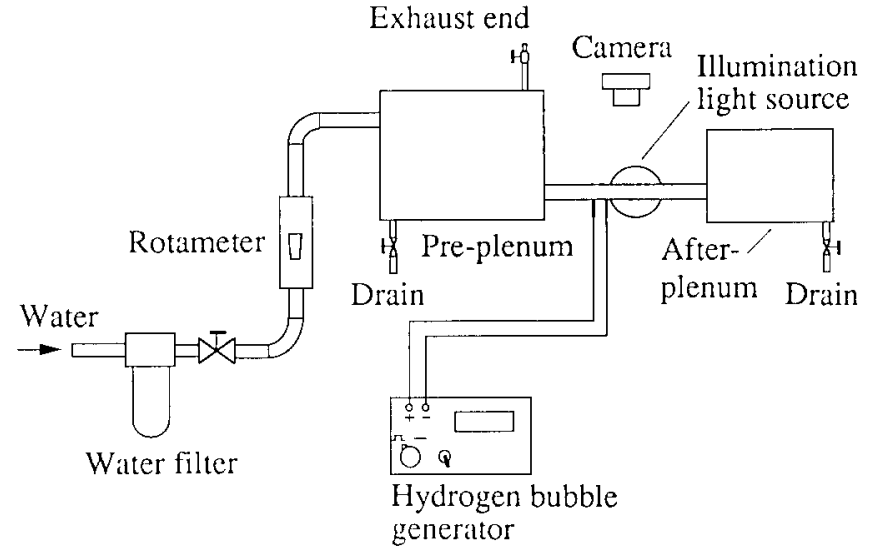

Fig. 4. Flow visualization experimental setup

is. As expected, $K_{x}$ grows as $L$ and $N_{x}$ increase, as seen in Fig. $5 \mathrm{c}$ and $\mathrm{d}$, respectively.

Pressure distributions were measured in a flow network with $\theta=60^{\circ}$, and in its half unit. Results for $R e=16,600$ are presented in Fig. 6 a. The vertical line at $L=8.89 \mathrm{~cm}$ corresponds to the center of flow intersection. Large pressure drops in both the flow network $\Delta p_{T}$ and the half unit $\Delta p_{H}$ occur in entrance and intersection regions due to the effect of bi-entrances, and turning and/or ramming, respectively. Each is followed by a recovery. The length of the pressure recovery region, $L_{r}$, is about three to four times $D_{h}$ downstream of the entrance region, and eight to ten times $D_{h}$ downstream of the flow intersection region, where $D_{h}$ is the hydraulic diameter of the flow channel. The difference between the two pressure drops, $\left(A p_{T}-\Delta p_{H}\right)$, represents the ramming loss. Figure $6 \mathrm{~b}$ shows the effect of $R e$ on $\Delta p_{H}$. As expected, the higher the flow, the larger $\Delta p_{H}$ is. The pressure drop and recovery at both the entrance and flow intersection regions diminish with a decrease in $R e$.

\subsection{Flow visualization}

Results of flow visualization using the water model (not shown) exhibit typical laminar and turbulent flow profiles, respectively. They imply that the flows are already full-developed, and that the entrance lengths of both the laminar and turbulence flows must be less than $8 D_{h}$ in this flow network.

The observation is in agreement, qualitatively, with the result obtained from pressure distribution in sect. 3.1. Hence, the entrance length is much less than the conventional empirical data of $\frac{L}{d}=0.06 R e$ for laminar flows and $\frac{L}{d}=$ $4.4 R e^{1 / 6}$ for turbulent ones in pipe (Robert and McDonald 1985). Figure 7 shows flow ramming in the intersecting zone. In the laminar-flow case, no intermixing occurs in the intersection area, as shown in Fig. $7 \mathrm{a}$ and $\mathrm{b}$ which are taken in different time after the hydrogen bubble generates. In contrast, turbulent flow at a lower Reynolds number, for example $R e=3,200$, is characterized by intermixing in the down- 

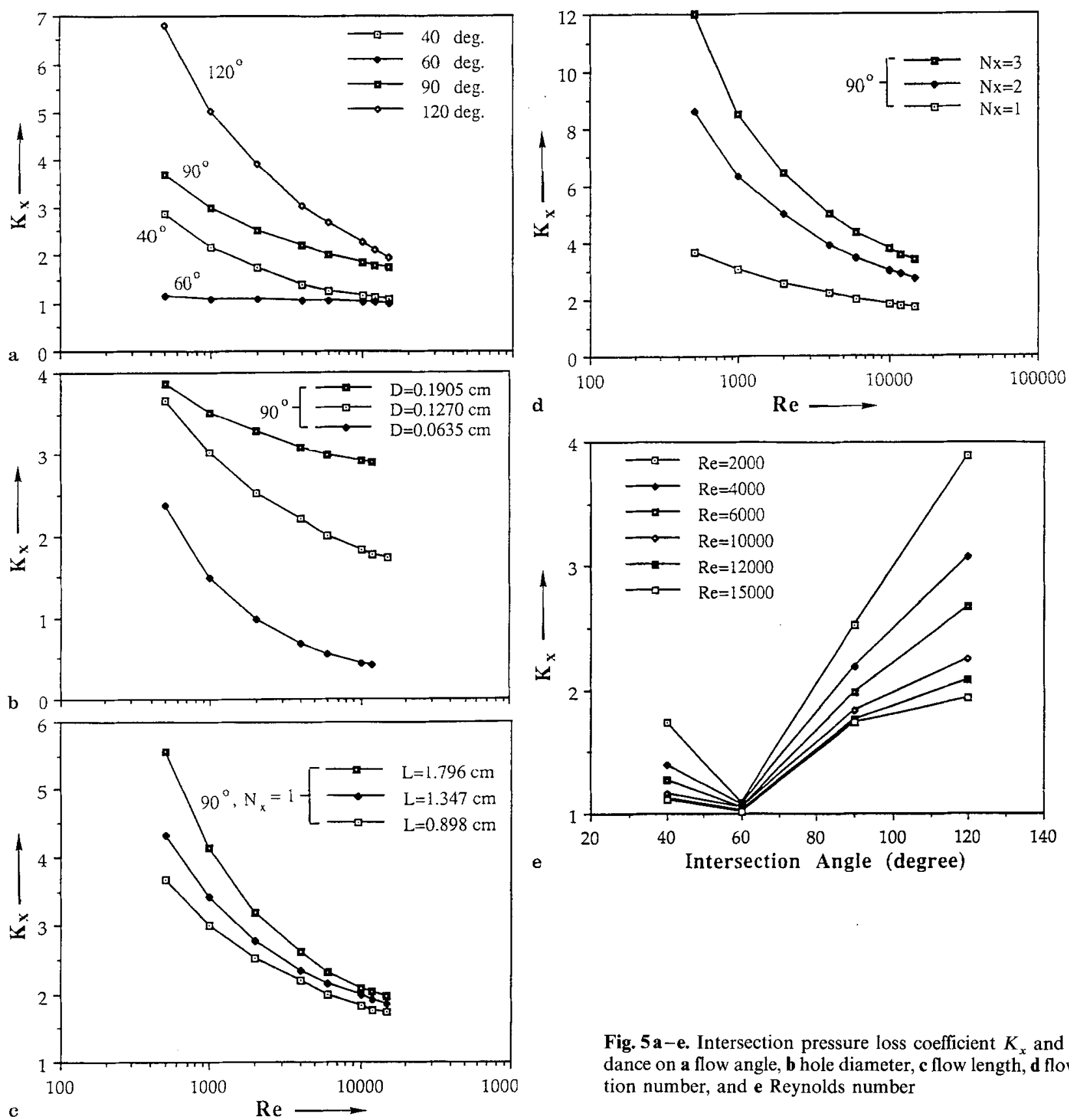

Fig. 5 a-e. Intersection pressure loss coefficient $K_{x}$ and its dependance on a flow angle, $b$ hole diameter, $\mathbf{c}$ flow length, $\mathbf{d}$ flow intersection number, and e Reynolds number

stream end of the intersecting zone, as shown in Fig. $7 \mathrm{c}$. As the Reynolds number is increased, intermixing propagates upstream. For example, Fig. $7 \mathrm{~d}$ shows that at $R e=5,000$, intermixing starts at the mid-portion of the intersecting zone. With hydrogen bubbles being released from one of the two intersecting channels, flow patterns in the post-intersecting region (not shown) indicate that at the Reynolds numbers of 3,200 and 5,000, the streak lines downstream of the intersection area shift toward the inner walls, forming long recirculation zones that stretch downstream until the exit $(L / d=9.6)$ with less flow through the other half of the channel.

\subsection{Mechanism of flow network}

A physical model is developed to interpret the mechanism of flow networks and to predict the intersection pressure loss coefficient, $K_{x}$. It is important for the optimum design of flow networks to use the model to explain why there exists a minimum $K_{x}$ in the $K_{x}-\theta$ relationship (Fig. 5).

The pressure loss across a flow network may be treated as superposition of one half each of a miter bend and a quadrant-edged orifice based on flow symmetry, as shown in Fig. 8. The reason for selecting the quadrant-edged orifice as a part of the superposition is based on the results of flow 

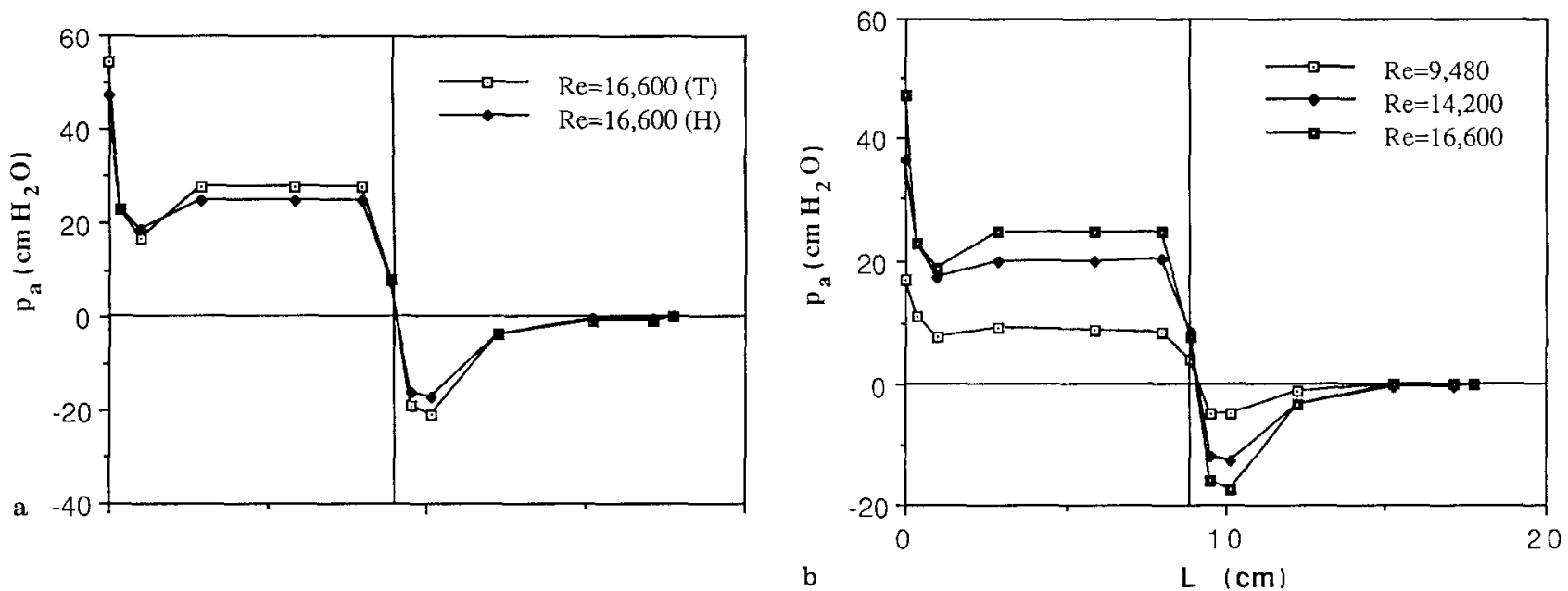

Fig. 6a and b. Pressure distribution in a flow network and its half unit; a flow network $(T)$ and its half unit $(H)$; b effect of Reynolds number (in half unit)
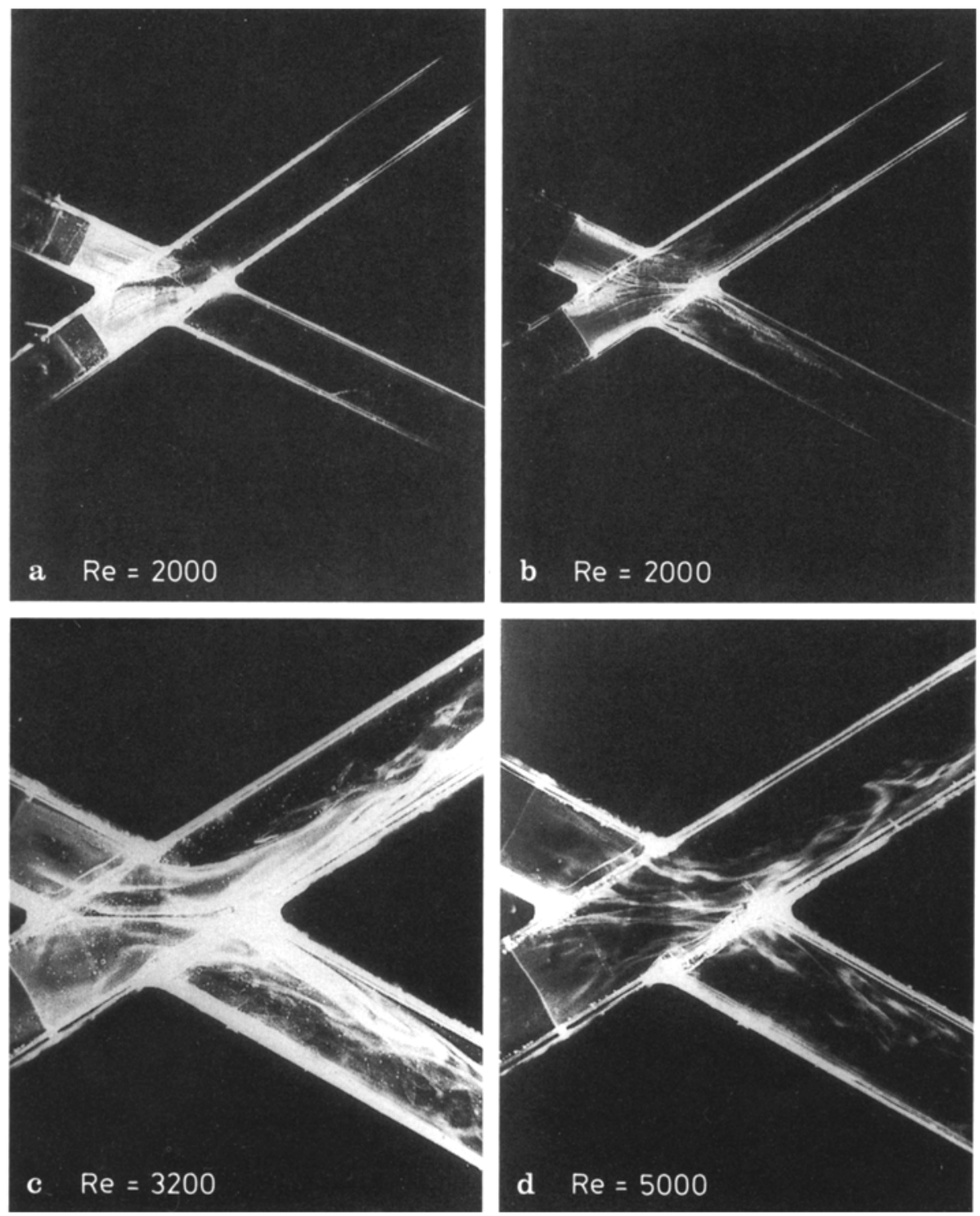

Fig. 7 a-d. Visualization of flow ramming in intersecting zone, $\mathbf{a}$ and $\mathbf{b}$ for laminar flow and $\mathbf{c}$ and $\mathbf{d}$ for turbulent flow 
visualization in which intermixing takes place in the midportion of the intersecting zone.

\subsubsection{Pressure loss in a miter bend}

The pressure loss in a bend is primarily induced by secondary flow and can be expressed using the equivalent length of a straight pipe as

$\Delta p_{b}=f \frac{L_{e}}{d} \frac{\varrho V^{2}}{2}$

Here, $\frac{L_{e}}{d}$ is determined from Fig. 9 (Robert and McDonald 1985).

According to the Blasius correlation for turbulent flow in smooth pipes,

$f=\frac{0.3164}{R e^{0.25}}$

One rewrites Eq. (11) as

$\Delta p_{b}=K_{b} \frac{\varrho V^{2}}{2 g_{c}}$.

Here $K_{b}$, the pressure loss coefficient for the miter bend, which is

$K_{b}=\frac{0.3164}{R e^{0.25}} \cdot \frac{L_{e}}{d}$.

Equation (14) is valid for $R e \leq 10^{5}$.

\subsubsection{Pressure loss through a quadrant-edged orifice}

The pressure loss through a quadrant-edged orifice can be expressed by the pressure loss coefficient as

$\Delta p_{0}=K_{0} \frac{\varrho V^{2}}{2 g_{c}}$.

The coefficient $K_{0}$ changes with Reynolds number, and diameter ratio $\beta$ (which is equal to $\left.\sqrt{\frac{a_{t}}{a}}\right)$. The data of $K_{0}$ is determined using Fig. 10 (Miller 1989).

It should be noted that in the present case, $\beta$ changes with the intersecting angle $\theta$. The relationship between $\beta$ and $\theta$ can be deduced as follows:

The throat area of the orifice is

$a_{t}=\frac{1}{2}\left(\pi b \frac{d}{2}\right)$.

Meanwhile, Fig. 8 gives

$d=\mathrm{H} \cos \left(\frac{\pi}{2}-\theta\right)$
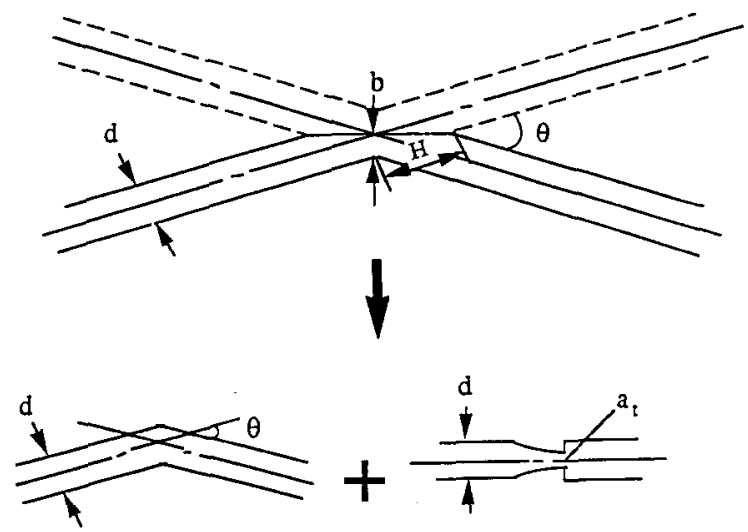

Fig. 8. Resolution of pressure loss in half unit of a flow network with a single intersection

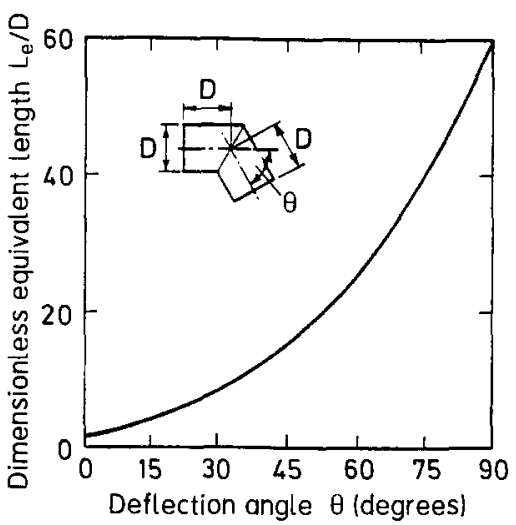

Fig. 9. Pressure losses for a miter bends

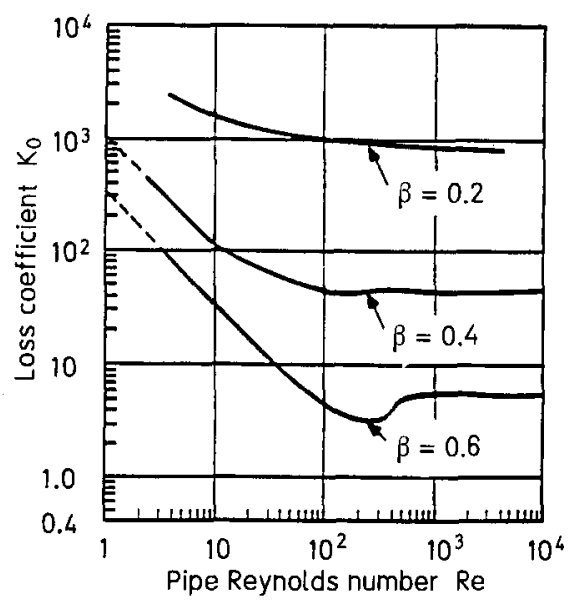

Fig. 10. Pressure loss coefficients for a quadrant-edged orifice

Table 2. Pressure loss coefficients $K_{0}$ and $K_{b}$ for $R e=10,000$

\begin{tabular}{llllllll}
\hline$\theta$ & $30^{\circ}$ & $40^{\circ}$ & $50^{\circ}$ & $60^{\circ}$ & $70^{\circ}$ & $80^{\circ}$ & $90^{\circ}$ \\
\hline$\beta$ & 0.719 & 0.729 & 0.743 & 0.760 & 0.781 & 0.808 & 0.841 \\
$K_{0}$ & 1.38 & 1.21 & 1.00 & 0.88 & 0.73 & 0.55 & 0.40 \\
$K_{b}$ & 0.26 & 0.39 & 0.58 & 0.77 & 1.00 & 1.42 & 1.90 \\
\hline
\end{tabular}




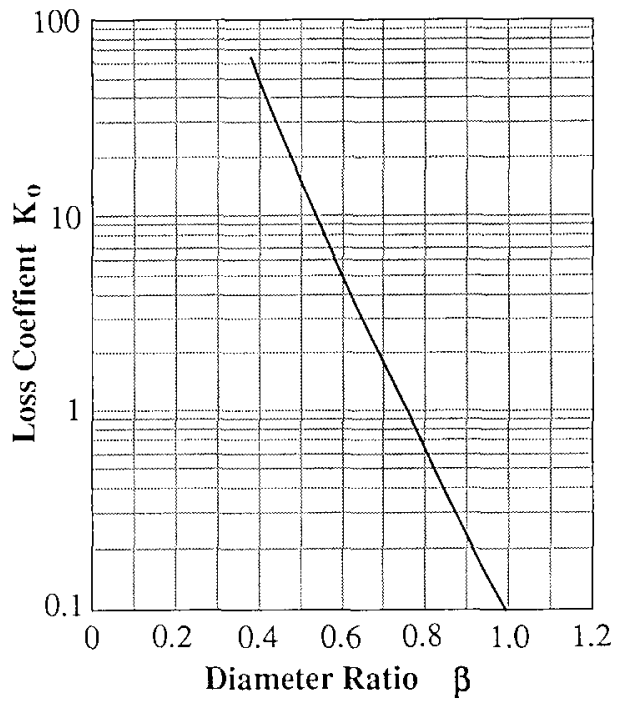

Fig. 11. $K_{0}-\beta$ relationship for $R e=10,000$

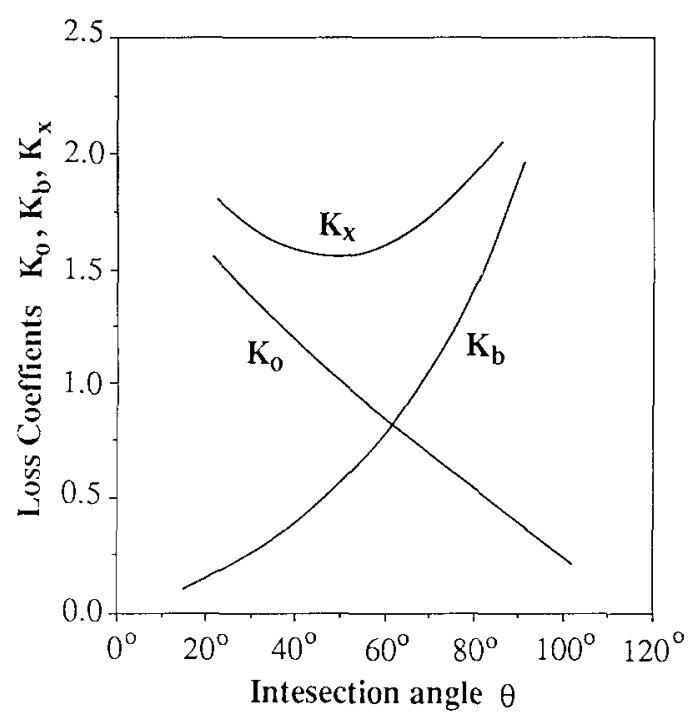

Fig. 12. Pressure loss coefficients $K_{0}, K_{b}$ and $K_{x}$ versus intersection angle 0 for $R e=10,000$

and

$b=H \sin \frac{\theta}{2}$.

Therefore,

$\beta=\sqrt{\frac{a_{t}}{a}}=\sqrt{\frac{\frac{\pi}{4} b d}{\frac{\pi}{4} d^{2}}}=\sqrt{\frac{b}{d}}=\sqrt{\frac{\sin \frac{\theta}{2}}{\cos \left(\frac{\pi}{2} \theta\right)}}$.
Figure 10 can be utilized to determine the $K_{0}-\beta$ relationship for a desired Reynolds number. Results for $R e=10,000$ are plotted in Fig. 11. The corresponding $K_{0}-\theta$ relationship can be obtained by using Eq. (16), and $K_{b}-\theta$, by Eq. (14) and Fig. 9. Results for $R e=10,000$ are presented in Table 2. $K_{0}$ and $K_{b}$ can be combined into one chart through a superposition, to yield the intersecting pressure loss coefficient $K_{x}\left(=K_{0}+K_{b}\right)$, which is depicted in Fig. 12.

Comparing Fig. $5 \mathrm{e}$ and Fig. 12, it is found that the minimum of $K_{x}$ occurs at close but different intersection angles. The disparity is caused by the limitation of discrete variety of the angle in the experiment and the error in the approximate analysis. Further experimental study and analysis are desirable, and the ramming loss should be taken into account in order to improve the model and its accuracy.

\section{Conclusions}

A systematic experiment has been performed to determine the flow characteristics in flow networks with various geometrical configurations. A new parameter has been derived which is called intersecting pressure loss coefficient, $K_{x}$. Its magnitude has been calculated, and is characterized by a minimum value at the intersection angle of $60^{\circ}$. The minimum $K_{x}$ is constant for any Reynolds numbers in the range of 500 through 15,000 .

A method has been developed to measure the ramming loss in a flow network using a blow-up model. It is revealed that the pressure recovery region downstream from the flow intersecting zone is much longer than that downstream from the entrance region. Flow visualization has confirmed results obtained from pressure distribution measurements and has provided a detailed interpretation of the mechanics of the ramming process. Only a small amount of mass exchange is observed between the two intersecting flows. A physical model has been developed to predict the intersection pressure loss coefficient in flow networks.

\section{References}

Robert, W. Fox; McDonald, A. T. 1985: Introduction to fluid mechanics. (3rd ed.). p. 370. New York: Wiley

Miller, R. W. 1989: Flow measurements engineering handbook (2nd ed.). pp. 6-34. New York: McGraw-Hill 